\title{
UNIFORMITY OF PROPERTIES IN ALLOY 706 THROUGH CONTROL OF FORGING
}

\author{
AND HEAT TREATMENT \\ M. M. Morra and P. Jepson \\ Wyman-Gordon Company \\ 244 Worcester Street \\ North Grafton, Massachusetts 01536-8001
}

\begin{abstract}
The effects of strain, heat treatment time and temperature, and cooling rate were examined for alloy 706. How these parameters can influence recrystallization and $\eta$ phase precipitation during forging and heat treatment will be demonstrated. These results are linked to the importance of controlling forging conditions to produce uniform strain and properties over different section thicknesses. The role of intergranular $\eta$ phase in LCF failure will also be shown.
\end{abstract}

\section{Introduction}

One of the keys to customer satisfaction, in the supply of forgings for turbine disc applications, is uniformity of properties. Uniformity, both from area to area within one forging, and from forging to forging. With very large forgings, which alloy 706 is typically used for, it is feasible to take mechanical specimens from integral test rings attached to each forging. There is no way, however, verification through testing of every area of the forging has the same properties as the integral test ring without destroying the forging. The cost of destroying a forging for test purposes is such that it must be done as infrequently as possible. A more cost effective approach is use of a combination of full scale finite element models (FEM) in combination with sub-scale experiments to simulate the thermo-mechanical histories of specific regions within the forging. Based on these analyses, the forger can then design processes to achieve substantially similar histories in every area of the forging. It is also necessary to control processing to ensure similar mechanical properties for every forging. Structure property relationships confirmed in the subscale simulations provide that link with mechanical properties.

This paper concentrates on process design rather than process control. The process referred to includes the steps necessary to take a triple-melted, homogenized, conditioned ingot through to a machined forging, with all treatments that affect bulk mechanical properties completed.

The first step in the process is billetization. Ideally, the process will mechanically homogenize the cast structure of the ingot and produce a uniform grain size. The dimensions of the billet are approximately the same as those of the ingot. Diameters in the 0.76 to $0.89 \mathrm{~m}$ range are

Superalloys $718,625,706$ and Various Derivatives

Edited by E.A. Loria

The Minerals, Metals \& Materials Society, 1997 
typical, with a length to diameter ratio of approximately two. The hot work stage in billetization is done at high temperature, well above the recrystallization temperature. Generating a uniform level of strain throughout the workpiece is key to producing a uniform microstructure in the billet. Generating a uniform level of strain starts with improved control over billetization of the ingot. One limitation of the upset and drawback process is that it generates very high strains in the center of the billet and low strains at the ends near the centerline. Wyman-Gordon has chosen a container upset and extrude method of billetization in order to obtain a more homogenous strain distribution with resulting uniform grain size in the billet. In this method, the ingot undergoes a series of container upsets, progressing into larger and larger diameter containers. In the final step, the piece is returned to its original diameter by extrusion. During each container upset extra strain is put into the material near the ends. The result is that at the end of the container upset sequence, the strain near the ends is greater than that at mid-height. This compensates for the fact that in extrusion, the first material through the throat and the last, are strained less than the material away from the ends.

Each hot work operation in the extrusion billetization sequence is complete within 3 to 4 minutes of the workpiece coming out of the furnace. 'Thus, surface cooling is minimal with almost no surface cracking, and high yields.

This method has produced very good results. Consistent results can be obtained with a minimum of one 'pot and extrude' cycle. In contrast, using 'upset and drawback', the process is typically done twice. Grain sizes of ASTM 2 to 4 are obtained after an annealing treatment in which any material that did not recrystallize during extrusion is allowed to recrystallize. The center material typical has a slightly coarser grain size than near the surface. This is a result of the relative difference in cooling rates between center and surface location seen in large diameter pieces. Because of the axisymetric geometry of extrusion, the process can be simulated using a 2-D FEM. In contrast, drawing-back would require 3-D modeling. The benefit here is that selection of extrusion process parameters can be rapidly made. Low time usage required for 2-D modeling results in faster feedback for process development. Multiple iterations of process schemes lead to better control over strain distribution in the piece. Also, the strain/temperature histories provided by the models can be can be immediately applied to subscale forgings for confirmation of microstructure and mechanical properties.

Once processed, the billet is upset-forged into either an open-die pancake shape, or into a contoured closed die. Achievement of an ASTM 5 grain size throughout a forging requires:

- Low forging temperature (and thus a high tonnage press)

- Achievement of an adequate strain in all areas

- Recrystallization during heat treatment.

Maintaining a uniform grain size can present a problem if the billet is forged down to a pancake in one operation. In this case, adiabatic heating can raise the temperature of the center of the workpiece (also the most highly strained area) by as much as $65^{\circ} \mathrm{C}$. Both these factors will result in nonuniform recrystallization. Heat transfer limitations cannot be resolved by slow forging, based on the large scale of the workpiece. The rate limiting step remains the conduction of heat away from the center. This issue must be addressed by dividing the operation into several steps. During each step the adiabatic heat load generated is small. In addition, the incorporation of wash-heats between steps allows the temperature to reequilibrate.

Achieving uniform recrystallization is also dependent upon generating sufficient strain throughout the workpiece. For example, if the billet is simply upset between flat dies, die-lock areas exist that do not achieve adequate strain. Wyman-Gordon addresses this problem in one of two ways, dependent upon the final shape to be achieved. 
One way is to forge dimples into the top and bottom surfaces to produce an intermediate shape. A strain contour map of the dimpling operation is shown in Figure 1. In the following operation, the dimples are flattened out again, as shown in the strain contour map in Figure 2.

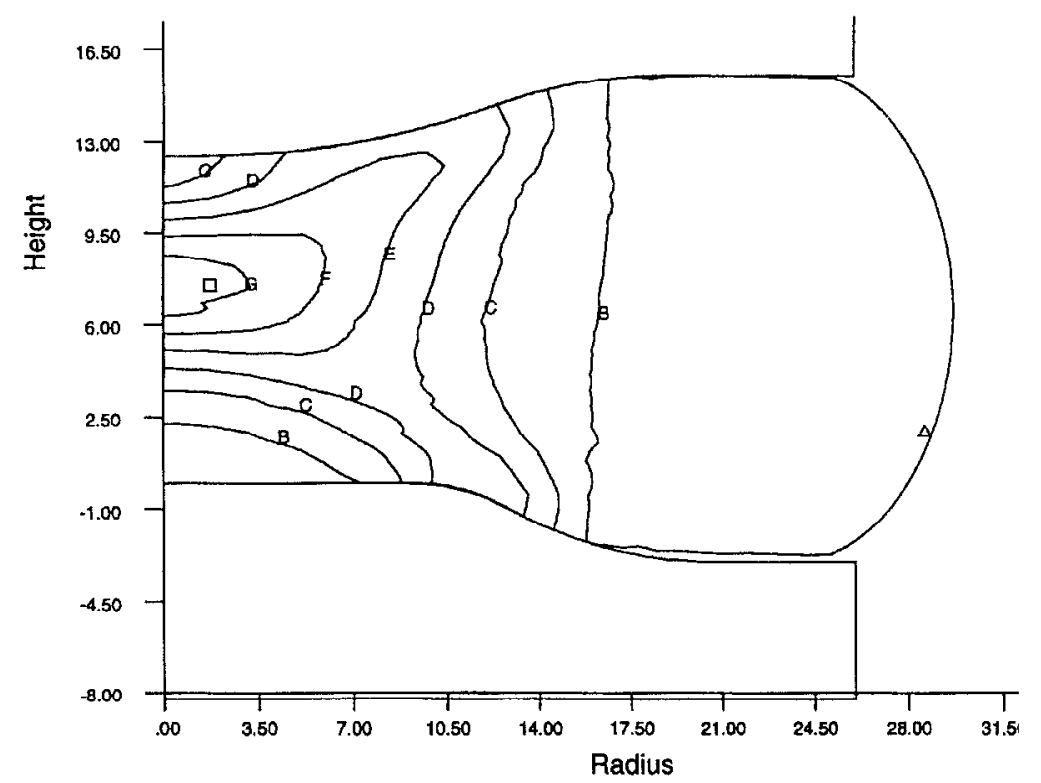

Figure 1. Strain contour map of dimpling operation. Strains $A(0.03)$ through $G(0.63)$ in 0.01 increments. $\Delta=0.037$ strain, $\square=0.69$ strain.

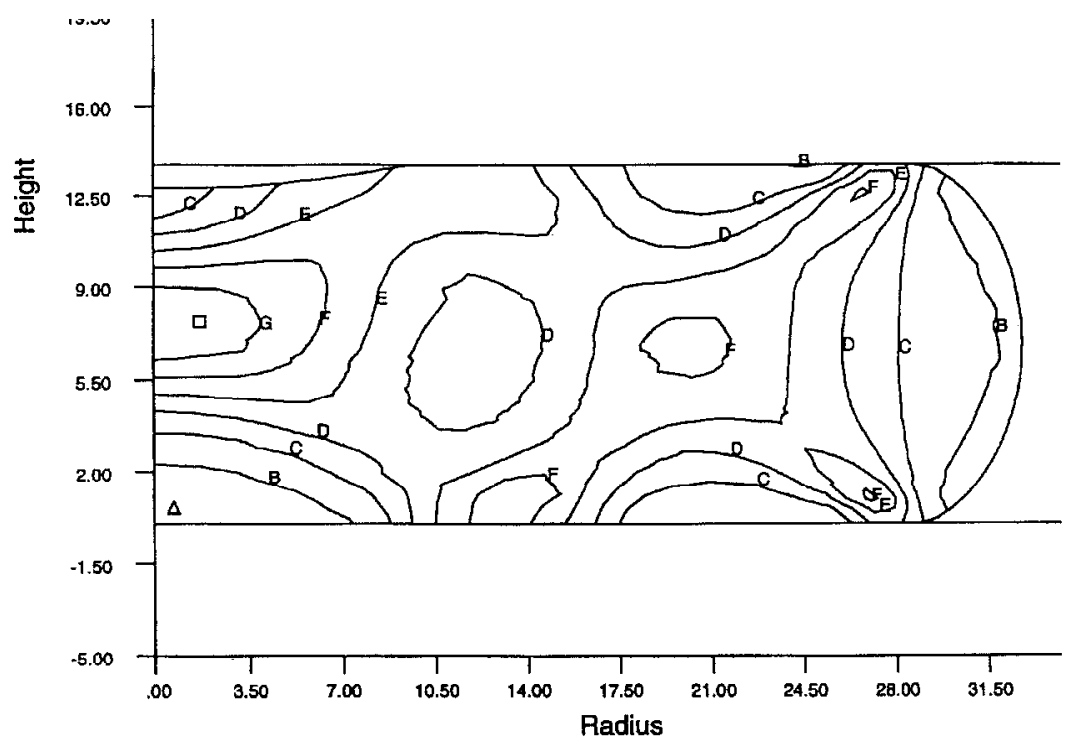

Figure 2. Re-flattening after dimpling to alleviate die-lock areas. Strains A (0.05) through $G$ (0.65) in 0.01 increments. $\Delta=0.053$ strain, $\square=0.78$ strain.

A second approach is to modify the friction coefficient between the workpiece and dies by using suitable intermediate layers. The result is an effectively friction-free interface that increases the minimum strain in the workpiece.

The strain and thermal histories of each of the operations have been effectively mapped using full scale FEM. The effects of strain on grain size after heat treatment, have been studied 
extensively, as have the effects on grain size of the different thermal histories (both in forging and in heat treatment) of near surface material and deep-seated material.

The remainder of this paper will illustrate an example of this approach to maintaining uniform grain size and limiting intergranular $\eta$ phase formation. The first section addresses specific factors related to maintaining grain size uniformity in the forged piece. These are; the effects of the strain distribution generated during forging, starting grain size, and the influence of fullscale (slow) cooling rates. The second part examines how temperature and heating/cooling rates influence the intergranular precipitation of $\eta$ phase. Finally, correlation between intergranular $\eta$ phase and high temperature low cycle fatigue (LCF) are presented.

\section{$\underline{\text { Experimental }}$}

This study was designed to encompass pre-forge starting grain sizes, strains, and a representative span in processing temperature. Large, double cone samples were forged to generate the strain distributions required. Full-scale forging thermal histories were achieved through specially designed insulation systems uscd during subscalc forging and post-forging cooling. The double cones were continuously monitored during processing (heat-up to forge to post-forge cool-down) using insitu buried thermocouples. Finite element modcls wcre run to simulate each of the subscale forge parameters with which thermal data was compared. The models were also used to map the final strain distribution after forging a given double cone geometry.

\section{Procedure}

\section{Material}

Two different grain sizes, ASTM 1 and 4, of alloy 706 were used for the starting materials. The chemistry of the starting material is given in Tablc 1 . Two double cone configurations were machined from these materials. One geometry was designed to produce bands of uniform strains over a wide, 0.2 to 0.8 , strain range. The starting gcomctry for this double cone is shown in Figure 3a. A second set of double cones was used to improve the analysis in the low, 0.05 to 0.3 , strain range. Their incorporation was necessary to climinate the possibility of cooling effects at the surface (low strain region) of the high $\Delta \varepsilon$ range double cone. A drawing of the starting geometry for this design is shown in Figure $3 \mathrm{~b}$. The post-forge, effective strain distributions were determined by FEM for temperatures of 954 and $996^{\circ} \mathrm{C}$.

Table 1. Chemistry of Alloy 706 Used. Weight Percent.

\begin{tabular}{ccccccccccccc}
$\mathrm{Ni}$ & $\mathrm{Fe}$ & $\mathrm{Cr}$ & $\mathrm{Nb}$ & $\mathrm{Ti}$ & $\mathrm{Al}$ & $\mathrm{Si}$ & $\mathrm{C}$ & $\mathrm{Mn}$ & $\mathrm{P}$ & $\mathrm{S}$ & $\mathrm{B}$ & $\mathrm{Mg}$ \\
\hline 41.5 & 37.5 & 15.9 & 3.00 & 1.66 & 0.23 & 0.02 & 0.015 & 0.03 & 0.004 & 0.0005 & 0.004 & 0.0003
\end{tabular}




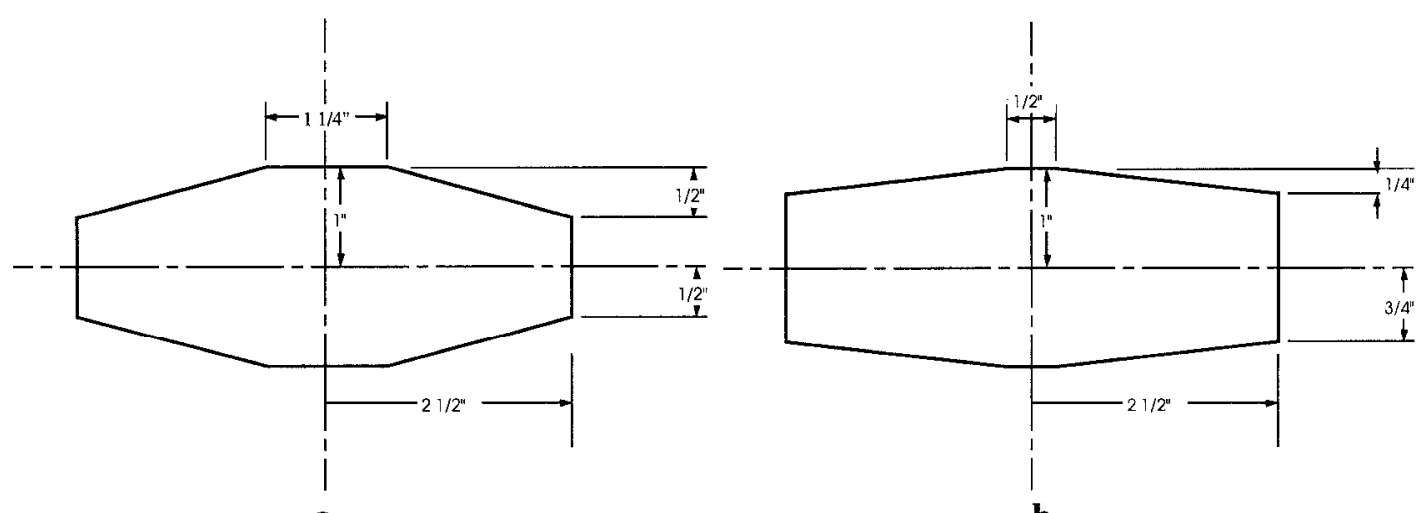

a.

b.

Figure 3. (a) High strain range double cone. (b) Low strain range double cone.

\section{Experiment Design}

The objective was to simulate the thermal conditions found at subsurface and center locations in a full-scale alloy 706 forging. Heating and cooling rates encountered during the forge preheat, forging, post-forge, and the solution anneal were extracted from production data and/or generated from thermal models for full-scale pieces.

The thermal response of a post forged double cone was determined using a test piece that duplicated the dimensions of an as-forged double cone. This allowed experimentation with various controlled cooling arrangements to achieve the post-forge cooling rates seen in fullscale forgings. Thermocouples were inserted at three positions in the piece, located along the mid-line of the test piece al radial depths from the surface of $12.7 \mathrm{Imm}, 25.4 \mathrm{Imm}$, and $38.1 \mathrm{Inm}$. The two inner thermocouples cooled at similar rates. The insulation/cooling setups were adjusted until the average cooling rate, as determined by a least squares fit, was equivalent for the three locations. The same procedure was followed for the actual double cones to insure a uniform cooling rate. An average post-forge cooling rate of $5.55^{\circ} \mathrm{C} / \mathrm{min}$. was achieved. Individual double cones were designated a preheat cycle and post-forge cooling schedule designed to simulate either subsurface or center locations in a full-scale forging.

For forging, each double cone underwent a specific preheat cycle at either 954 or $996^{\circ} \mathrm{C}$. A furnace with programmable controller, calibrated to $\pm 3.3^{\circ} \mathrm{C}$, was used for the pre-heat. The double cones were forged immediately after the designated preheat time had elapsed. Astroloy dies that were induction heated to $871^{\circ} \mathrm{C}$ were used. The pieces were forged with a press head speed that varied from 127 to $51 \mathrm{~mm} / \mathrm{min}$. during the forge cycle. After post forge cooling the pancakes were sectioned into 8 equal radial slices. One slice was preserved to examine the asforged condition. A second slice was solution annealed above the $\eta$ solvus temperature following specific production heat treatment cycles, then aged. (1) The remaining slices were retained in the as-forged condition for future heat treatment studies.

Each slice was maintained in an intact condition for metallographic preparation. The intact radial cross-sections permitted the strain contours that were determined by FEM models to be precisely mapped onto the actual samples. The strain fields were scribed onto the polished faces of the samples and optical micrographs taken in each of the strain fields. Grain size determination was performed using the linear intercept method. A minimum sampling of 100 grains was used for each analysis. The same pieces were repolished and electrolytically etched using an ammonium sulfate $(10.5 \mathrm{~g})$ citric acid $(10.5 \mathrm{~g})$ in $1000 \mathrm{~mL}$ water solution. Etching was done using a Ta cathode at $10 \mathrm{~V} / 0.01-0.004 \mathrm{~A}$, for 15 minutes followed by ultrasonic cleaning. This etchant is a gamma phase etchant that leaves $\eta, \delta, \gamma^{\prime}, \gamma^{\prime \prime}$, and carbides in 
relief(2) The samples were examined for intergranular $\eta$ phase formation using scanning electron microscopy (SFM).

Data, used for examining correlation between intergranular $\eta$ phase, high temperature LCF fracture morphology, and LCF life, were collected from a representative sampling of alloy 706 $\mathrm{LCF}$ bars tested at $398^{\circ} \mathrm{C}$. Metallographic cross-section were prepared from the test samples after SEM fractographs were obtained from the fracture surfaces. The cross-sections were etched using the same electrolytic etching procedure outlined above. A large number of high magnification SEM micrographs were taken from each of the cross-sections to provide a statistical base for quantitative phase analyses. Phase analyses were done using NIH 'Image Version 1.58' software from digitized SEM images.

\section{$\underline{\text { Results }}$}

\section{Grain Size}

A comparison of grain size versus strain and location was made at both forge temperatures, for starting grain sizes of ASTM 1 and 4. Center and subsurface locations did not show a significant difference in final grain size, within the error scatter. The only trend observed is a decrease in grain size with increasing strain. Comparing all data, 954 and $996^{\circ} \mathrm{C}$ pre-heat temperatures had minimal impact on final grain size. Within the thermal conditions applied to these samples, strain is the primary factor controlling final grain size.

For the ASTM 1 starting grain size material, a stable (post-anneal) final grain size in the ASTM 2 to 3 range was evident for strains of 0.3 and lower. Grain size then increased by ASTM 1 from 0.5 to 0.8 strain. For material with a starting grain size of ASTM 4 it was evident that the final grain size produced in this material shows less dependence on strain. Here, final grain size falls into the ASTM 4 to 4.5 range for all the strains examined. The data sets for the materials forged at $996^{\circ} \mathrm{C}$ shown trends similar to those seen in the $954^{\circ} \mathrm{F}$ data. The ASTM 1 starting grain size material shows a clear dependence on strain, with an increase of approximately ASTM 1.5 over a range of 0.05 to 0.8 strain. The trends for all the data are illustrated in Figure 4. Stratification of the data based on starting grain size and strain becomes apparent. The plotted data are shown identified by starting grain size alone. The trend seen in Figure 4 shows final grain size to be relatively independent of strain for the ASTM 4 material, but increasing with increasing strain for the coarser grain material. At high strain, above 0.65 , the two data sets begin to merge, indicating an independence from starting grain size.

\section{Eta Phase and LCF}

The first part of this study focused on grain size. The second factor of importance in alloy 706 is control of intergranular $\eta$ phase $\left[\mathrm{Ni}_{3}(\mathrm{Nb}, \mathrm{Ti})\right]$ precipitation. Coprecipitation of $\eta$ and $\delta$ phase appears to be common in Ni-Fe base superalloys with high $\mathrm{Nb}$ and Ti contents. $(3,4)$ Alloys 903, 907, Pyromet CTX1, and 706 have microstructural features that are common to both high $\mathrm{Nb}$ alloys that form $\delta$, such as alloy 718 , and high Ti/Al ratio alloys that form $\eta$, such as alloy A286.(5) Moll, et al. reported that both $\eta$ phase, hexagonal $\left(\mathrm{Ni}_{3} \mathrm{Ti}\right)$, and $\delta$ phase, orthorhombic $\left(\mathrm{Ni}_{3} \mathrm{Nb}\right)$, form as intergranular, acicular precipitates in alloy 706. (4) Alloy Pyromet CTX-1 has also been reported to precipitate both $\delta$ and $\eta$ phases.(3) Experimental heats of this alloy have also been reported to form an unidentified intergranular "Laves-like" phase.(3) Smith describes an acicular precipitate named epsilon $(\varepsilon)$ in alloy 907 that has a hexagonal structure.(6) Epsilon phase, $\mathrm{Ni}_{3}(\mathrm{Ti}, \mathrm{Nb})$, occurs both intergranularly and intragranularly in this alloy and is reported to be distinct from either $\eta$ phase or $\delta$ phase. This mixed character 
intergranular phase has also been linked to intergranular fracture seen in alloy 905.(7) The presence of intergranular $\eta$ phase has been also been linked to a reduction in alloy strength but with no loss of ductility. (8,9) It is sometimes implicitly assumed that $\eta$ phase is strictly stoichiometric $\mathrm{Ni}_{3} \mathrm{Ti}$, with little solubility for other elements. Studies on alloy X750, however, have indicated that $\eta$ phase does have some solubility for $\mathrm{Fe}, \mathrm{Cr}, \mathrm{Nb}$, and Al. (10) For the purposes of this paper, intergranular $\eta$ phase is the acicular/platelet morphology $(\eta-\delta) / \varepsilon$ hybrid phase, the precipitation conditions for which are based on available TTT diagram information. (1)

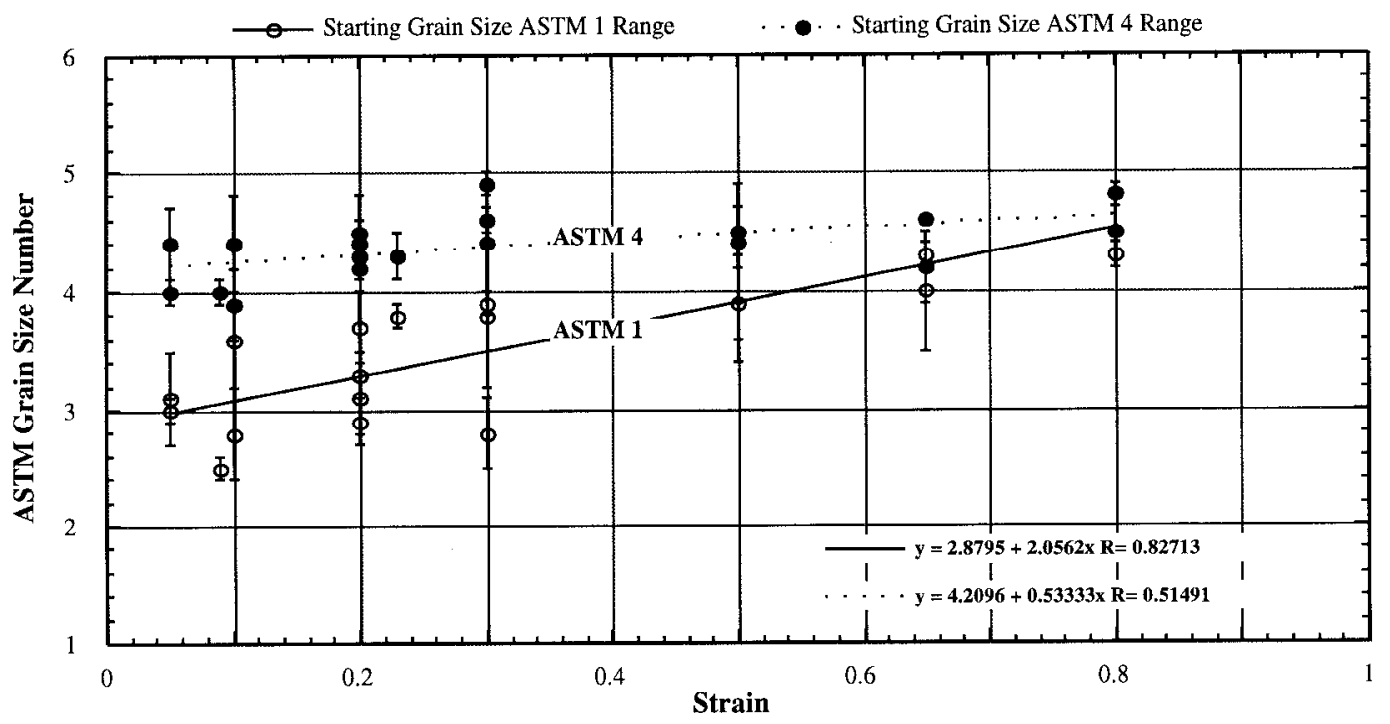

Figure 4. Final, post anneal, grain size for alloy 706 forged at 954 and $996^{\circ} \mathrm{C}$.

Based on analyses of sub versus super $\eta$ solvus forging conditions for the as-forged double cone materials, it is apparent that intragranular $\eta$ phase precipitation at $954^{\circ} \mathrm{C}$ is a function of strain. Higher volume fractions of this phase form at higher strains. Intergranular $\eta$ phase was mostly absent at the lower forging temperature. Longer holding times at temperature (subsurface locations) produced no $\eta$ phase. Short pre-forge holding times at $954^{\circ} \mathrm{C}$ (center location) produced significant $\eta$ phase precipitation in high strain material, above 0.6 strain. This corresponds with the assumption that the center represents the worst case for heating and cooling rates with regard to precipitation of $\eta$ phase. Super $\eta$ solvus anneal also eliminated these locations of precipitation. At $996^{\circ} \mathrm{C}$, neither form of $\eta$ phase was absent.

Preliminary investigations of alloy 706 have shown a relationship between low cycle fatigue life and intergranular $\eta$ phase. LCF test data are shown plotted by grain size in Figure 5 . Separating the data by grain size range clarifies the correlation between cycles to failure and percent intergranular $\eta$ phase by isolating grain size / LCF interactions. For example, the worst case (low cycles to failure) occurs when a large grain size is combined with a high percentage of intergranular $\eta$ phase. A small grain size combined with a low percentage intergranular $\eta$ phase would be represented at the high end of cycles to failure. The beneficial contribution of smaller grain sizes appears to occur at approximately 7000 cycles.

The fracture morphology of alloy 706 LCF tests at $398^{\circ} \mathrm{C}$ typically show cleavage-like facets. The micrographs, along with companion fractographs shown in Figure 6, illustrate both the 


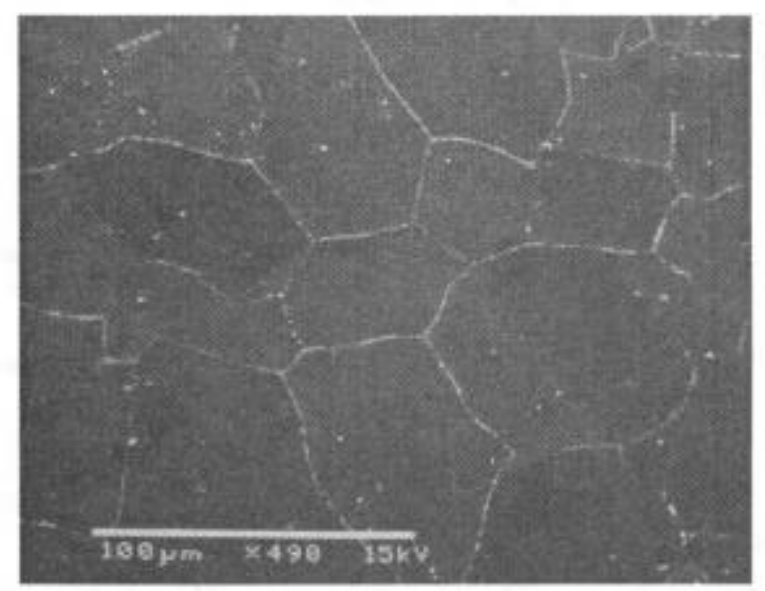

a.

N

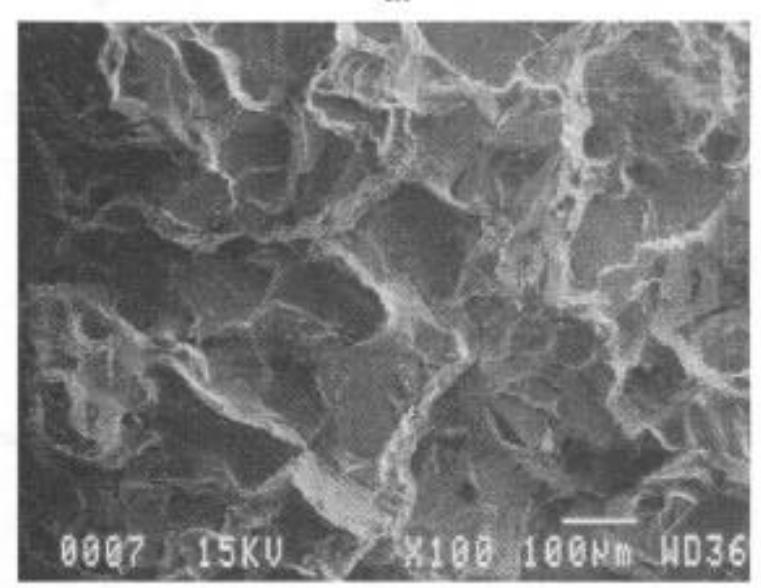

b.

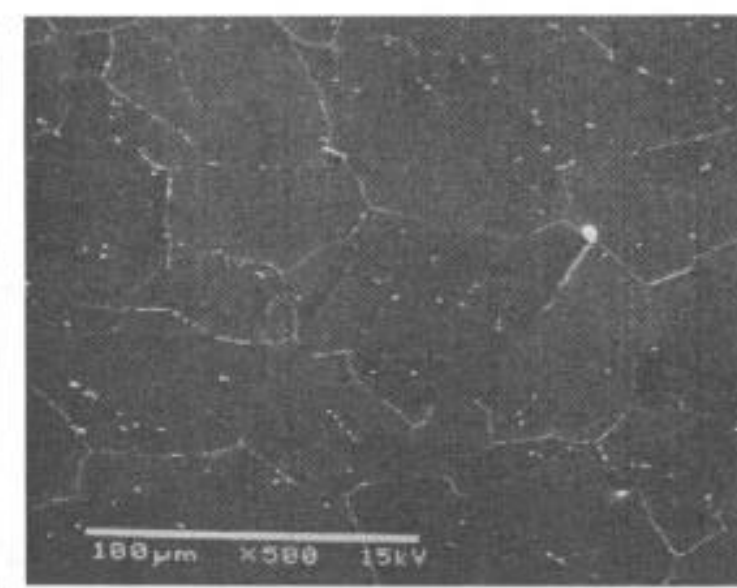

c.

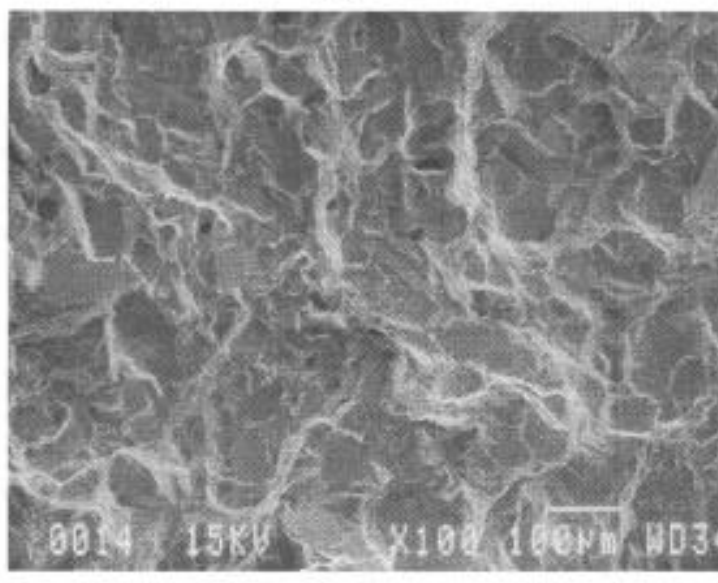

d.

Figure 6. (a) (b) SEM micrograph and fractograph, respectively, of $398^{\circ} \mathrm{C}$ LCF sample that failed at 4500 cycles, grain size intergranular $\eta$ phase, and $57 \%$ grain boundary coverage by $\eta$ phase. (c) (d) SEM micrograph and fractograph, respectively that failed at 9200 cycles, grain size ASTM 5, 0.87 area $\%$ intergranular $\eta$ phase, and $12 \%$ grain boundary coverage by $\eta \mathrm{pl}$ 


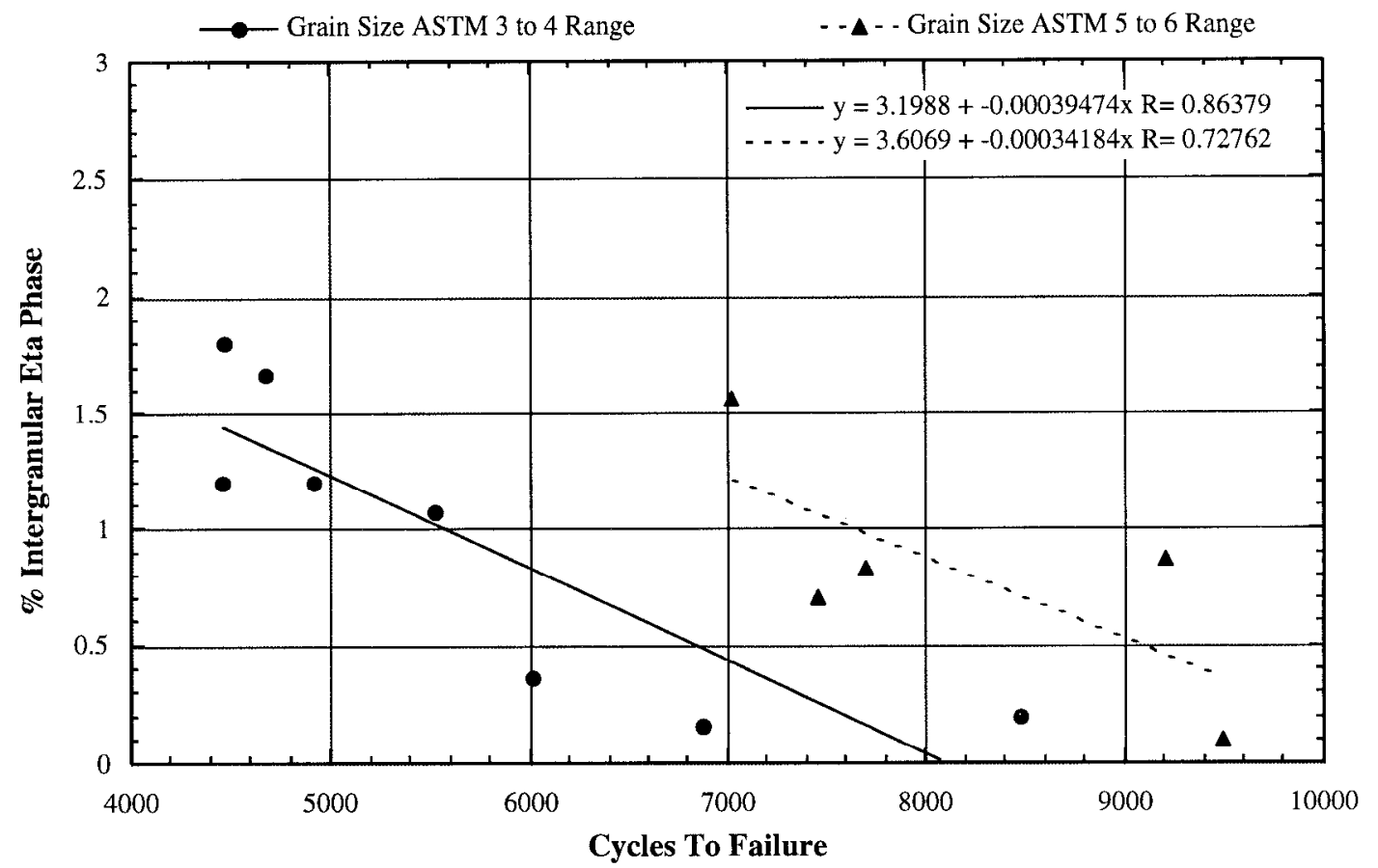

Figure 5. Percent intergranular $\eta$ phase (based on area percent) versus cycles to failure at $398^{\circ} \mathrm{C}$.

facet fracture morphology and the correlation to the percent intergranular $\eta$ phase. In Figure 6 the percent grain boundary coverage by $\eta$ phase is also given. It provides a relative measure of intergranular $\eta$ phase that compensates for differences in grain size. High resolution SEM examination of the facet fracture surfaces show no evidence of microductility. The surfaces are typically smooth and/or decorated by slip traces. The facets appear to correspond with intergranular and twin boundary crack initiation and fracture during LCF testing. Facets appear in the fractures in this alloy from room temperature into the $400^{\circ} \mathrm{C}$ range, although the percentage varies. Cross-sections through the facet fracture regions of LCF fracture surfaces are shown in Figures $7 \mathrm{a}, 7 \mathrm{~b}, 7 \mathrm{c}$, and $7 \mathrm{~d}$. Preliminary evidence suggests that $\eta$ located on grain and twin boundaries acts as a crack initiation site. (11) Interrupted tests typically show multiple internal and surface initiation sites corresponding to $\eta$ decorated grain and twin boundaries.

\section{Discussion}

Two interrelated and controlling factors determined the final grain size. The primary factor was the amount of strain. The secondary factor was the starting grain size.

At low strains, primary MC carbides are the main sites for nucleation of grains.(12,13) A small fraction of the recrystallized grains form at existing grain boundaries, and this fraction decreases as the grain size increases. As a result, a non-uniform grain size distribution is found in low strain areas of material with a starting grain size of ASTM 1. The non-uniformity manifests itself as a distribution of large, unrecrystallized grains, along with fine, recrystallized grains. When a statistically significant number of grain diameters are measured, the average final grain size is smaller than that of the starting material. This produces the apparent 


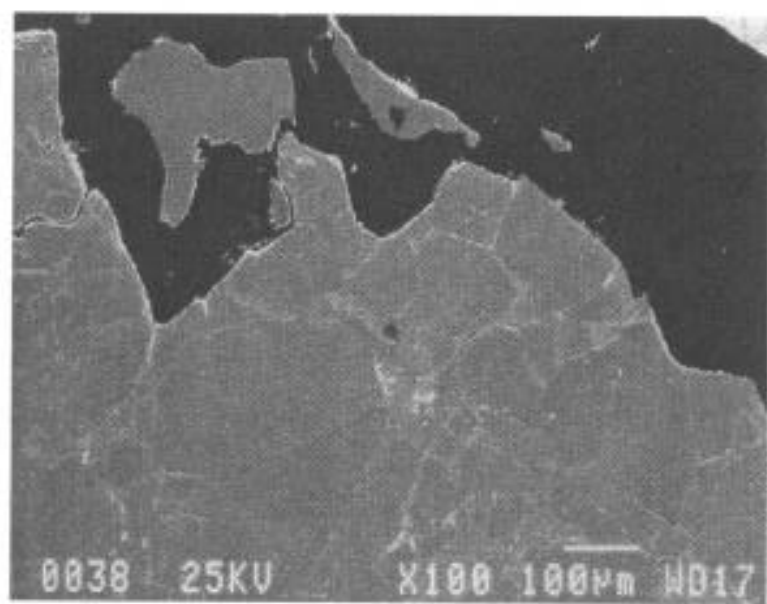

a.

జ్ల

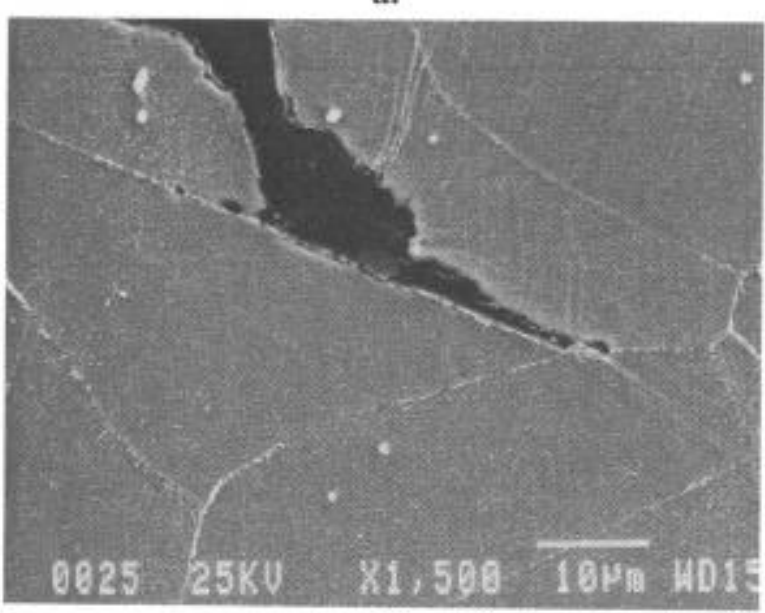

c.

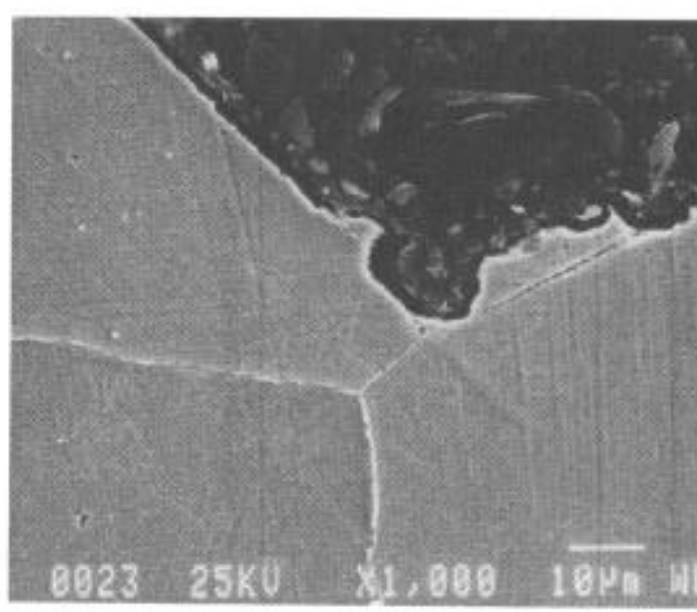

b.

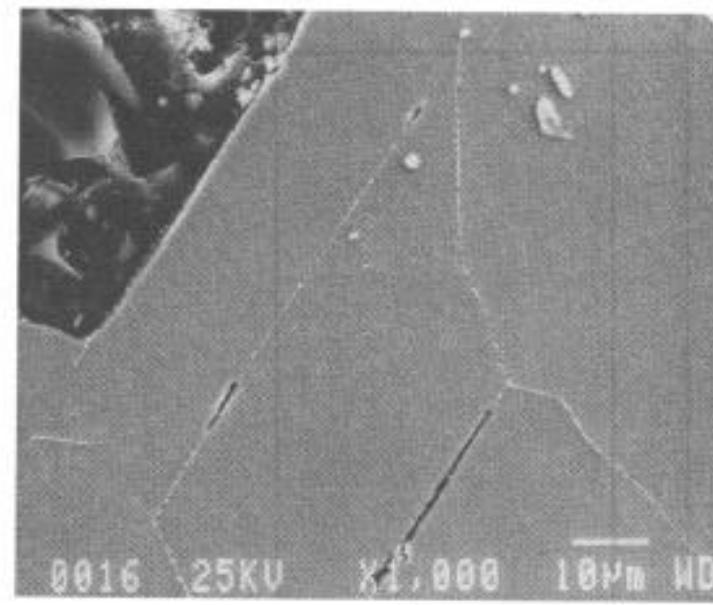

d.

Figure7. SEM micrographs of cross-sections through $398^{\circ} \mathrm{C}$ LCF test samples. (a) Low magnification cross-section. ( through facet at fracture surface. (c) Separation at grain boundary decorated with $\eta$ phase. (d) Facet along $\eta$ decorated 
reduction in grain size seen in the low strain, ASTM 1, material after processing. Grain boundary nucleation predominates at higher (0.5) strains in this material.(14) The finer grain starting material, in contrast, has a greater number of grain boundary nucleation sites. Assuming the number of MC carbides are similar in the two materials, the ASTM 4 material can be expected to nucleate a greater number of grains, even at low strains. Because the starting grain size is finer, and there are more new grains nucleated, the ASTM 4 material appears to maintain a constant grain size as a function of strain. At high strains, above 0.5 strain, the final grain sizes are similar for both materials since the number of possible nucleation sites increases with increasing strain.(14)

Forge pre-heat temperature ( 954 versus $996^{\circ} \mathrm{F}$ ) had minimal effect on final grain size. Grain sizes in surface and center locations, based on cooling/heating rates, were similar. Preheat times, center versus surface, had no effect on final grain size, but did have an impact on intragranular $\eta$ phase precipitation when in combination with strains above 0.6 .

Intergranular $\eta$ or $\eta / \delta$ hybrid phase appears to act as strong crack initiation sites in LCF. It's effect on LCF is mitigated by a fine grain size and exaggerated by coarse grain size. The goal of the process design should be to refine grain size by generating a uniform and sufficiently high strain throughout the forging. Starting with fine grain precursor, billet material, is clearly beneficial.

\section{$\underline{\text { Acknowledgments }}$}

We would like to thank Bruce Silun and Wayne Prunier for their help in designing and skill in carrying out the subscale experiments.

\section{$\underline{\text { References }}$}

1. K. A. Heck, "The Time-Temperature-Transformation Behavior of Alloy 706", Superalloys 718, 625, 706 and Various Derivatives, ed. E. A. Loria, (Warrendale, PA, TMS, 1994), 393404.

2. M. M. Morra, R. G. Ballinger, and I. S. Hwang, "INCOLOY 908, a Low Coefficient of Expansion Alloy for High-Strength Cryogenic Applications: Part I. Physical Metallurgy", Metall. Trans. A., 23A (1992), 3177-3192.

3. D. R. Muzyka, C. R. Whitney, and D. K. Schlosser, "Physical Metallurgy and Properties of a New Controlled-Expansion Superalloy", J. Metals, 27 (7) (1975), 11-15.

4. J. H. Moll, G. N. Maniar, and D. R. Muzyka, "The Microstructure of 706 a New Fe-Ni-Base Superalloy”, Metall. Trans. A., 2 (1971), 2143-2151.

5. M. C. Ottmann Cloier, and C. Leymonie, "Structural Transformations and Mechanical Properties of 'Two Non-magnetic Alloys (Inconel 718 and ASTM A286)", Material Science and Engineering, 1 (1984), 91-100.

6. D. F. Smith, Low-Expansion Superalloys, Huntington Alloys, Huntington, W Va.

7. L. T. Summers and E. N. C. Dalder, "An Investigation of the Cryogenic Mechanical Properties of Low Thermal Expansion Superalloys", Advances in Cryogenic Engineering, 28 (1986), 73-80. 
8. "The Metallurgy of Nickel-Iron Alloys", The Superalloys, ed. C. T. Sims and W. C. Hagel (NY, NY: W. C. Wiley, 1972), Chapter 4.

9. C. P. Sullivan and M. J. Donachie, Jr., "Microstructures and Mechanical Properties of IronBase (-Containing) Superalloys", Metals Engineering Quarterly, 11 (1971), 1-11.

10. A. N. Ritter and C. L. Briant, "The Effect of Second Phase Particles on Fracture in Engineering Alloys", Treatise On Materials Science and Technology, Vol. 25, ed. C. L. Briant and S. K. Banerji, (NY., NY: Academic Press, 1983), 59-123.

11. D. Eylon and W. R. Kerr, "Fractographic and Metallographic Morphology of Fatigue Initiation Sites", Fractography in Failure Analysis, ed. B. M. Strauss and W. H. Cullen, Jr. (Philadelphia, PA: American Society for Metals, 1977), 235-248.

12. F. J. Humphreys, "Nucleation of Recrystallization in Metals and Alloys with Large Particles", Recrystallization and Grain Growth of Multi-Phase and Particle Containing Materials, ed. N. Hasen, A. R. Jones, and T. Leffers, (Roskilde, Denmark, RIS $\emptyset$ National Laboratory, 1980), 36-44.

13. R. Sandström, "Criteria for Nucleation of Recrystallization Around Particles", Recrystallization and Grain Growth of Multi-Phase and Particle Containing Materials, eds. N. Hasen, A. R. Jones, and T. Leffers, (Roskilde, Denmark, RIS $\emptyset$ National Laboratory, 1980), 4549.

14. M. J. Luton and C. M. Sellars, "Dynamic Recrystallization in Nickel and Nickel-Iron Alloys During High temperature Deformation", ACTA Metallurgica, 17 (1969), 1033-1043. 